\title{
Energy Management Strategy for Commercial Buildings Integrating PV and Storage Systems
}

\author{
He ZHANG ${ }^{1,2}$, Arnaud DAVIGNY ${ }^{1,2}$, Jonathan SPROOTEN ${ }^{1,2}$, \\ Benoit ROBYNS ${ }^{1,2}$, Frederic COLAS ${ }^{1,3}$, Yvan POSTE ${ }^{4}$ \\ ${ }^{1}$ University of Lille Nord of France, Laboratory of Electrical Engineering and Power \\ Electronics of Lille (L2EP) \\ ${ }^{2}$ Ecole des Hautes Etudes d'Ingénieur (HEI), Lille, France \\ ${ }^{3}$ Ecole Arts et Métiers ParisTech (AMPT), Lille, France \\ ${ }^{4}$ Groupe Auchan, Croix, France \\ \{he.zhang, arnaud.davigny, jonathan.sprooten, benoit.robyns\}@ hei.fr, \\ Frederic.COLAS@ENSAM.eu, yposte@auchan.com,
}

\begin{abstract}
This paper presents an energy management strategy for a commercial building in supermarket application. Some objectives are established as load shedding, to reduce the electricity bill and the $\mathrm{CO}_{2}$ emissions of commercial building, such as supermarkets, in using PV and storage systems. An energy management supervision strategy based on the rules of the electricity bill will be presented. This paper focuses on the supervision strategy with the help of fuzzy logic. It is shown, with the help of simulations and comparisons, that the energy bill cost and the $\mathrm{CO}_{2}$ emissions can be reduced by using the solution proposed.
\end{abstract}

Keywords: Photovoltaic (PV) systems, fuzzy logic, storage system, energy management, commercial building, supermarket

\section{Introduction}

In recent years, the Energy European legislations seek to lower the $\mathrm{CO}_{2}$ emissions and the fossil energy consumption by the development renewable energy [8][9][10][11]. One of the priority is "Building performance requirements and very low energy buildings ("passive houses")" "because the largest cost-effective savings potential lies in the residential (households) and commercial buildings sector (tertiary sector), where the full potential is now estimated to be around $27 \%$ and $30 \%$ of energy use, respectively" [11]. It is indicated in [11]:"In residential buildings, retrofitted wall and roof insulation offer the greatest opportunities, while in commercial buildings, improved energy management systems are very important".

To reach these objectives, we consider a supermarket connected to the power network and associated to photovoltaic and storage system. Some energy management strategies, developed with the help of fuzzy logic, for the storage system are presented. It is shown in this paper that the storage system can also adjust the power supplied by grid in the peak period and off-peak period in order to reduce the electricity bill and the $\mathrm{CO}_{2}$ emissions.

In section 2, the connexion configuration of the supermarket is defined. The objective, the constraints and means of action of this supervision are also introduced in this section. The strategy adapting the way to calculate the electricity bill is presented in section 3 . 
Then, the fuzzy logic based supervision is deployed in section 4 . The simulation results and comparisons are shown in section 5. The conclusion is given in section 6 .

\section{Models, configuration and objectives}

Fig. 1 shows the connexion configuration of a commercial building in supermarket application and the architecture of the supervision system which will be presented in the follow section. There is a PV system and a storage system installed in parallel with the supermarket load. All these equipments are installed behind the electric meter.

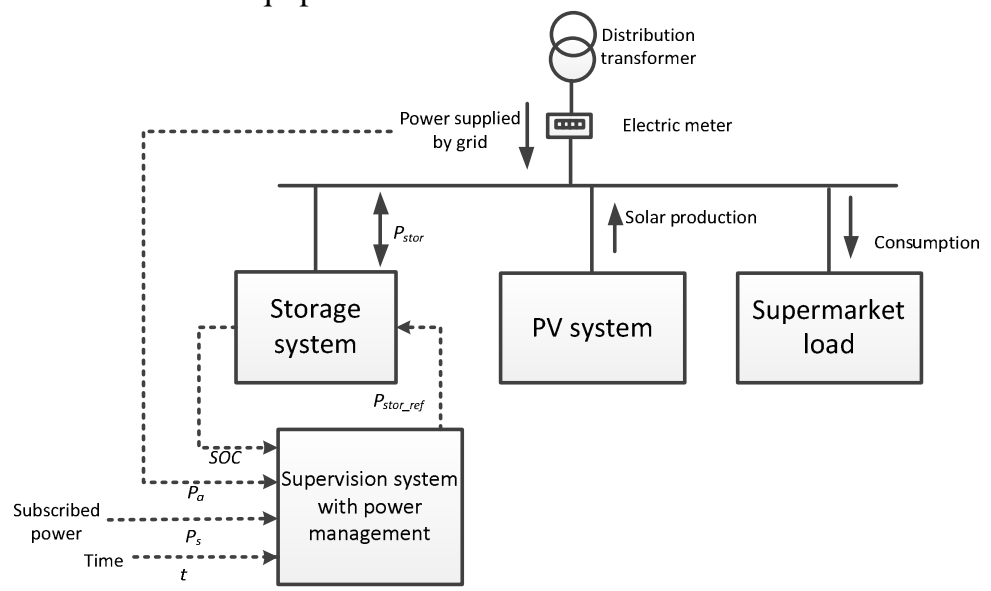

Fig. 1 The connexion configuration of a commercial building, supermarket application and the architecture of the supervision system.

A general model of storage system is used [1] as shown in Fig. 2, $P_{\max }$ is the output power limit; $\tau_{\text {stor }}$ is the time constant of the storage system and $W_{\text {stor }}$ is the energy stored by the storage system. The PV system and supermarket load are presented by a production or load profile shown in Fig. 3.

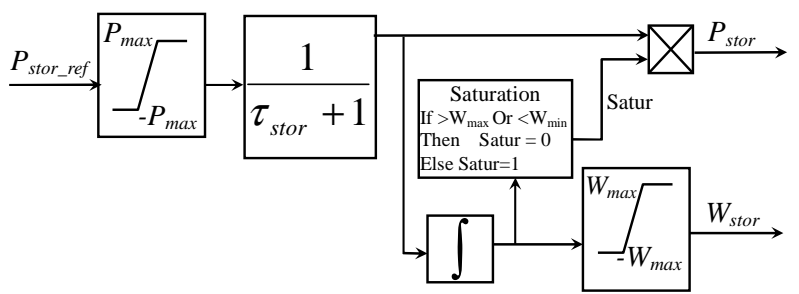

Fig. 2 Simplified model of the storage system

In a supermarket, there are several types of electric load: food refrigeration equipment, lighting systems, air handling systems, computer and cash management system etc.

In order to design a generalized supervision strategy, a fictive supermarket based on real consumption profile and statistical laws is created. Fig. 3 shows the total consumption power profiles of this fictive supermarket for one week. We can note that in Sunday (day 7) and in the night of everyday when the supermarket is closed, the power 
consumption is much lower than when it is open in the daytime.

PV system is modelled by a production profile based on the irradiance data supplied by Photovoltaic Geographical Information System (PVGIS)[8]. Neither the weather influence, nor daily difference of the sunrise and sunset moment are not taken into account.

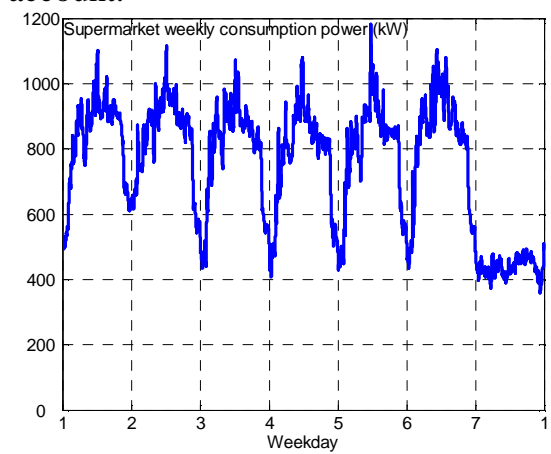

a) Weekly consumption power profile

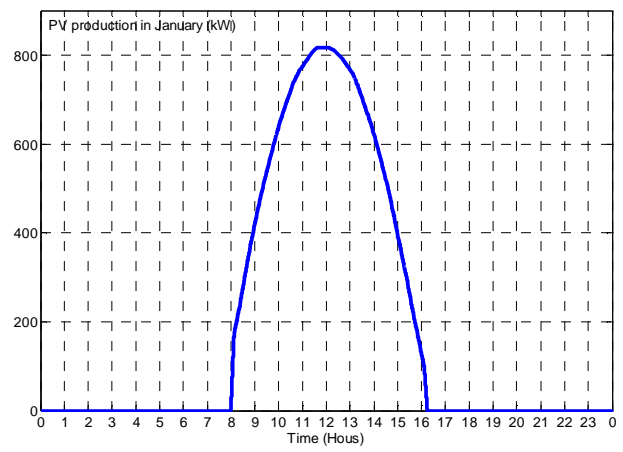

b) Daily PV production profile

Fig. 3 Consumption and production profile of supermarket

Table 1 summarize the objectives, the constraints and means of action of the energy management strategy. Because of the different electricity prices of each pricing periods, the energy management strategy will benefit this different to reduce the electricity bill and the $\mathrm{CO}_{2}$ emissions by balancing the consumption of peak and off-peak periods. The storage system is used to achieve the power balancing.

The subscribed power is another constraint. The subscribed power is a limitation of the consumption power. The load should not pass through this limitation, otherwise, it will be invoiced punitively by a much higher price.

Table 1 Objectives, constraints and means of action of the energy management strategy

\begin{tabular}{|c|c|c|}
\hline Objectives & Constraints & Means of action \\
\hline $\begin{array}{l}\text { To reduce the electricity bill. } \\
\text { - To balance between the power } \\
\text { of peak and off-peak periods to } \\
\text { reduce the } \mathrm{CO}_{2} \text { emissions. } \\
\text { - To ensure the energy } \\
\text { availability. }\end{array}$ & $\begin{array}{l}\text { - The electricity price of } \\
\text { different periods. } \\
\text { - The limit of the } \\
\text { subscribed power. } \\
\text { - The limit of the } \\
\text { storage capacity. }\end{array}$ & $\begin{array}{l}\text { - Reference power } \\
\text { of the storage } \\
\text { system. }\end{array}$ \\
\hline
\end{tabular}

\section{Rules of the energy management supervision strategies}

This part will focus on firstly the computation of the electricity bill, secondly the principles of the energy management strategy.

\subsection{Electricity bill}

The electricity bill is composed by three parts: the annual premium, the active consumption and the reactive consumption. The active consumption composed by two 
costs: consumption cost (cost by $\mathrm{kWh}$ ) and punishment cost if it is applicable (when supplied power pass over the subscribed power).

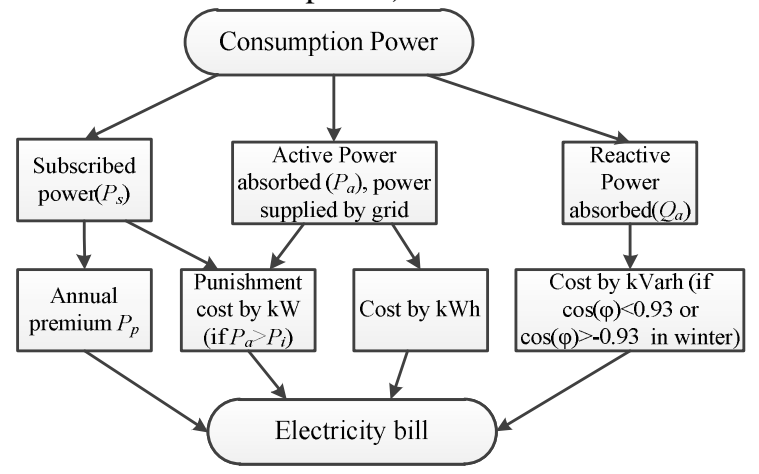

Fig. 4 The composition of an electricity bill

As mentioned above, the annual premium is calculated from the subscribed power $P_{s}$. This power is calculated according to the subscribed power defined in different pricing period $P_{i}$.

Equation (1) shows how to calculate the annual premium where $P_{p}$ is the total annual premium (€), $P_{k W}$ is the price by power ( $\left.€ / \mathrm{kW}\right), k_{i}$ is a period coefficient given by the electrical power company and $P_{i}$ is the subscribed power $(\mathrm{kW})$ according to the pricing period.

$$
\begin{aligned}
& P_{s}=\sum_{i=1}^{n} k_{i} \times\left(P_{i}-P_{i-1}\right) \quad \text { where } P_{0}=0 \\
& P_{p}=P_{k W} \times P_{s}
\end{aligned}
$$

Table 2 shows an example of the price table for 3 different pricing periods in winter.

Table 2 An example of price table for different pricing period in winter [13]

\begin{tabular}{c|c|c|c}
\hline & Peak period in & Shoulder period & Off-peak period \\
& winter(PPW) & in winter(SPW) & in winter(OPW) \\
$k_{i}$ & $k_{l}=1$ & $k_{2}=0.77$ & $k_{3}=0.38$ \\
$P_{k W h}(€ / k W h)$ & 0.1151 & 0.07662 & 0.04641 \\
\cline { 2 - 4 }$P_{k w}(€ / k W)$ & \multicolumn{3}{|c}{66.12} \\
\hline
\end{tabular}

The pricing period will be presented in section 4 .

\subsection{Principles of energy management strategy}

According to the objectives, the constraints mentioned in Table 1 and the prices shown in Table 2, the principles of the energy management supervision are listed as follow:

1. Don't pass over the subscribed power.

2. During the peak period, reduce the supplied power by the grid in order to reduce the electricity bill.

3. Ensure the availability of the storage system for the next pricing period. Charge the storage system during the off-peak period or the shoulder period only if it is really necessary.

4. The PV production should be consumed or stored by storage system priority. If 
there is exceeded power still, it will then be send to grid if the purchase agreement allows the supplied power to be negative.

\section{Fuzzy logic based energy management supervision strategies}

As mentioned above, there are several objectives to face for the supervision system. Fuzzy logic is an adapted tool to solve this kind of problem [2][3][4].

In section 3.2, the principles of energy management strategy are listed. These principles can be translated into several rules according to the different pricing periods.

According to the objective mentioned above, the variables to supervise (input) are the State Of Charge (SOC) of the storage system and the difference between the subscribed power and the load power $(\Delta P)$. The means of action (output) of the supervision system is the reference power $P_{\text {stor } r e f}$ to control the storage system. Initially, this reference is considered as the reference to control the storage system. Furthermore, it can be also considered as a reference to guide the load shedding, the consumption, but not only the storage system.

According to the different pricing periods, the objectives of the supervision strategy will be different. The pricing periods are split in 6 operation modes. The Table 3 shows different pricing periods and operation modes.

Table 3 Pricing periods and operation modes

\begin{tabular}{c|l|c|l}
\hline $\begin{array}{c}\text { Pricing } \\
\text { period }\end{array}$ & \multicolumn{1}{|c|}{ Description } & $\begin{array}{c}\text { Operation } \\
\text { mode }\end{array}$ & \multicolumn{1}{c}{ Description } \\
\hline \multirow{2}{*}{ PPW } & $\begin{array}{l}\text { 9h 11h and } 18 \mathrm{~h} \sim 20 \mathrm{~h} \text { from } \\
\text { Monday to Friday }\end{array}$ & PPW1 & $\begin{array}{l}\text { 9h 11h when the PV } \\
\text { production is great }\end{array}$ \\
\cline { 3 - 4 } SPW & $\begin{array}{l}7 \mathrm{~h} \sim 9 \mathrm{~h}, 11 \mathrm{~h} \sim 18 \mathrm{~h} \text { and } \\
20 \mathrm{~h} \sim 1 \mathrm{~h} \text { from Monday to } \\
\text { Friday }\end{array}$ & PPW2 & $\begin{array}{l}\text { 18h 20h when there's no } \\
\text { more PV production }\end{array}$ \\
\cline { 3 - 4 } & $\begin{array}{l}1 \mathrm{~h} \sim 7 \mathrm{~h} \text { from Monday to } \\
\text { Friday and all of the } \\
\text { weekend and the day off. }\end{array}$ & $\begin{array}{l}\text { 7h 9h and 11h 18h which is } \\
\text { followed by a PPW period }\end{array}$ \\
\cline { 3 - 4 } OPW & OPW1 & $\begin{array}{l}\text { 20h 1h which is followed by } \\
\text { an off-peak period }\end{array}$ \\
\cline { 3 - 4 } & $\begin{array}{l}\text { 1h 7h from Monday to Friday } \\
\text { and Saturday when the } \\
\text { supermarket is opened }\end{array}$ \\
\hline
\end{tabular}

The supervision strategy will be established separately according to the different operation mode shown above.

Fig. 5 shows a chart representation of this fuzzy logic supervision. This graphical tool was presented in [5][6] and helps us to design the supervision strategies for different operation modes. The operating modes listed above are represented with rounded rectangles and the states of the system are represented by transitions. The three pricing period are shown in N1.1, N1.2 and N1.3. In each pricing period, there are different operation modes whose the transition condition is shown in Table 3. Fig. 6 is an example of a single pricing period, off-peak period and its two operation mode. The objectives corresponding the different operation modes are shown in the bloc N1.1.1 and N1.1.2. 
The objectives of each operation mode are shown in Table 4, the numbers show the priority of objectives.

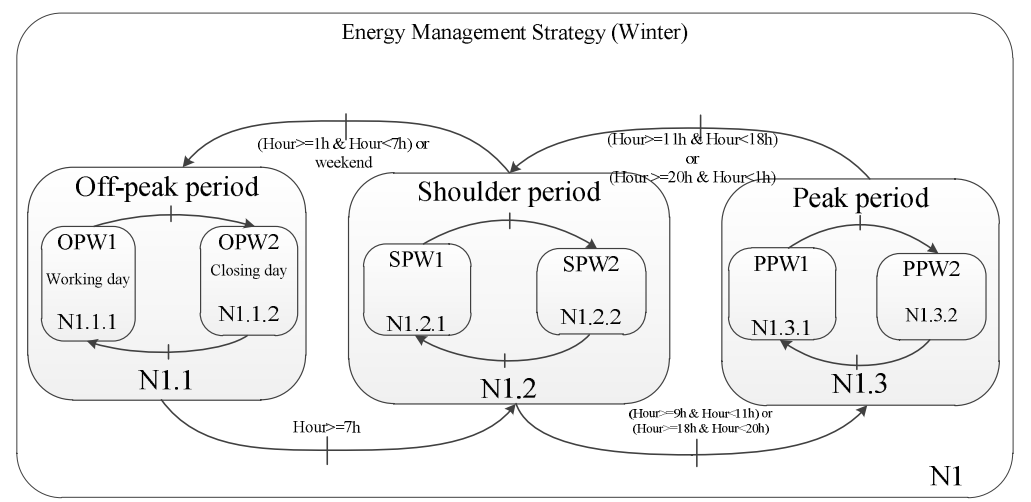

Fig. 5 Chart representation of the fuzzy logic supervision strategies

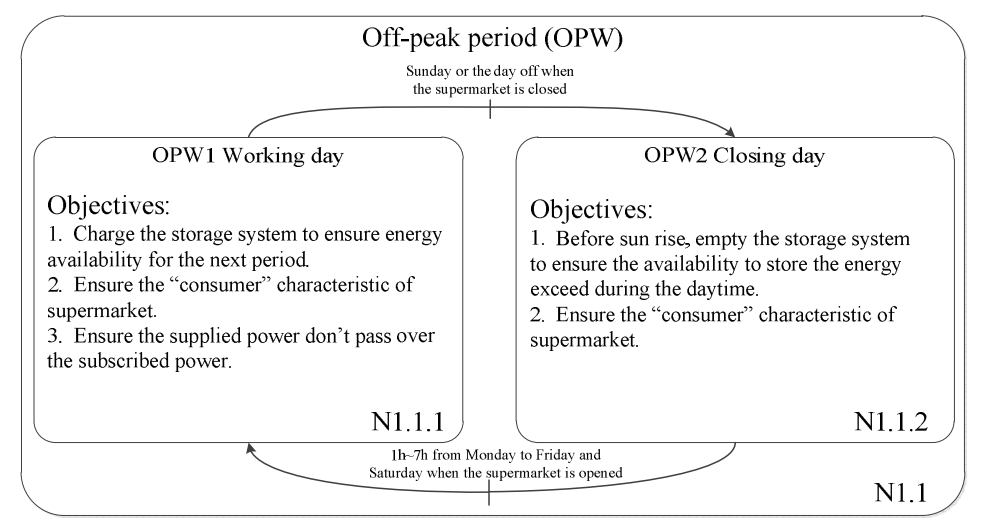

Fig. 6 Detail for a single pricing period which has two operation modes

Table 4 Objectives of each operation mode

\begin{tabular}{|c|c|}
\hline $\begin{array}{c}\text { Operation } \\
\text { mode }\end{array}$ & Objectives \\
\hline PPW1 & $\begin{array}{l}\text { 1. To discharge the storage system to reduce the supplied power by the } \\
\text { grid. } \\
\text { 2. To ensure the supplied power don't pass over the subscribed power. } \\
\text { 3. To ensure the energy availability of storage system, charge the storage } \\
\text { system to ensure the availability for the next period. } \\
\text { 4. PV production should be consumed or stored by storage system priority. }\end{array}$ \\
\hline PPW2 & $\begin{array}{l}\text { 1. To discharge the storage system to reduce the supplied power by grid. } \\
\text { 2. To ensure the supplied power don't pass over the subscribed power. } \\
\text { 3. To ensure the energy availability of storage system. }\end{array}$ \\
\hline SPW1 & $\begin{array}{l}\text { 1. To ensure the supplied power don't pass over the subscribed power. } \\
\text { 2. To discharge the storage system to reduce the supplied power by grid. } \\
\text { 3. PV production should be consumed or stored by storage system priority. } \\
\text { 4. To ensure the energy availability of the storage system, only if it is }\end{array}$ \\
\hline
\end{tabular}




\begin{tabular}{c|cc}
$\begin{array}{c}\text { Operation } \\
\text { mode }\end{array}$ & \multicolumn{1}{c}{ Objectives } \\
\hline SPW2 & $\begin{array}{c}\text { necessary (SOC is small), charge the storage system to ensure the } \\
\text { availability for the next period. }\end{array}$ \\
\hline OPW1 & $\begin{array}{l}\text { Same as the SPW1 except the energy availability of storage system is not a } \\
\text { majorement to meet. }\end{array}$ \\
\hline OPW2 & $\begin{array}{l}\text { To charge the storage system to ensure energy availability for the next } \\
\text { period. } \\
\text { To ensure the supplied power don't pass over the subscribed power. } \\
\text { PV production should be consumed or stored by storage system priority. }\end{array}$ \\
\hline 1. & $\begin{array}{l}\text { Before sun rise, empty the storage system to ensure the availability to } \\
\text { store the energy exceed during the daytime. }\end{array}$ \\
PV production should be consumed or stored by storage system priority. \\
To ensure the supplied power don't pass over the subscribed power.
\end{tabular}

As shown in Fig. 1, the architecture of the supervision system is according to the objectives mentioned in Table 1 . There are four inputs: $P_{a}$, absorbed active power (the power supplied by grid); $P_{i}$, the subscribed power according to the pricing period; SOC, the State Of Charge and $t$, the time. There is only one output which corresponds the means of action noted in Table 1.

We take an example of operation mode PPW1 to explain the implantation of fuzzy logic supervision.

\subsection{Operation mode PPW1}

During this period, the PV production will be important and the electricity price is expensive. The objectives of the supervision strategy are shown in Table 4:

Equation (2) shows the convention of the power difference $\Delta P$ where $P_{i}$ presents the subscribed power of each pricing period as mentioned in (1) and $P_{a}$ presents the active power absorbed as shown in Fig. 4.

$$
\Delta P=\left(P_{i}-P_{a}\right) / P_{i} \times 100 \%
$$

Fig. 7 illustrates the convention of the $\Delta P$ and the different fuzzy levels that will be mentioned in the fuzzy rules.

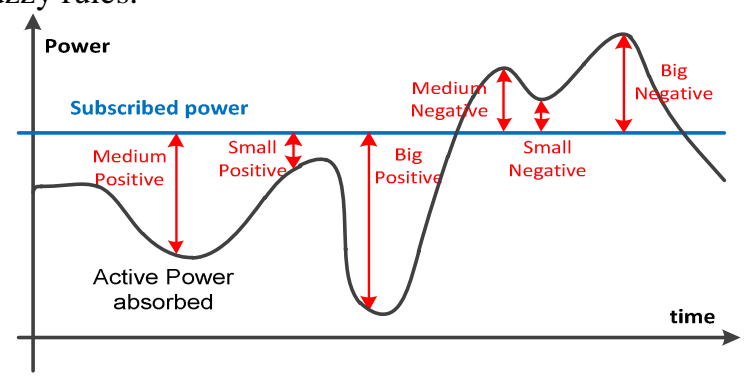

Fig. 7 Power convention and the different fuzzy levels

A fuzzy logic strategy includes three classical parts [7]: fuzzification, inference, and defuzzification.

\subsubsection{Fuzzification}

The two input variables membership functions are shown in Fig. 8. 
As mentioned above in section 3.2, one of the principles of energy management is to ensure that the grid power doesn't pass over the subscribed power. So, the membership function of $\Delta \mathrm{P}$ is not symmetrical around 0 .

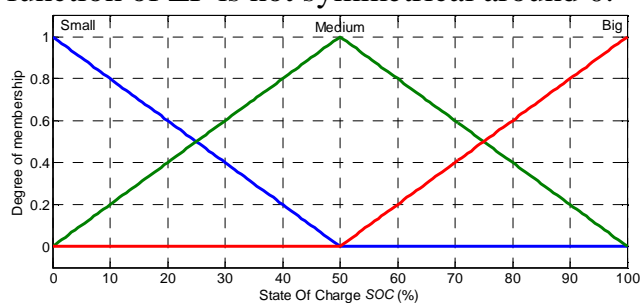

a)SOC of the storage system

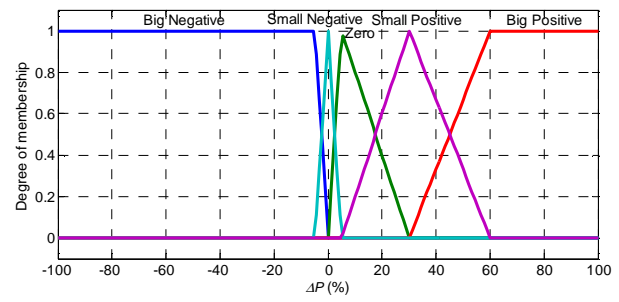

b)Power difference between the subscribed power and supplied power

Fig. 8 Membership functions of input variable for fuzzy energy management strategy

\subsubsection{Inference}

The fuzzy rules are expressed as follow:

IF $\triangle P$ is Small Positive AND $S O C$ is Medium, THEN Discharge Medium the storage system.

IF $\triangle P$ is Negative AND $S O C$ is Medium, THEN Discharge Great the storage system.

Etc...

These rules are defined according to the objectives shown in the Table 4. Thanks to these rules, according to the actual situation (the electricity price, the consumption, the subscribed power, the state of charge of the storage system etc.), the supervision system has different behavior to adapt intelligently the situation.

Table 5 shows the corresponding fuzzy rules for the PPW1 strategy

( $\mathrm{S}=$ Small, $\mathrm{M}=$ Medium, $\mathrm{B}=\mathrm{Big}, \mathrm{Z}=\mathrm{Zero}, \mathrm{P}=$ Positive, $\mathrm{N}=$ Negative, $\mathrm{C}=$ Charge, $\mathrm{D}=$ Discharge, $\mathrm{G}=\mathrm{Great}$ )

Table 5 Fuzzy rules: Power reference of storage system of PPW1 strategy

\begin{tabular}{|l|l|l|l|l|l|l|}
\cline { 2 - 7 } \multicolumn{2}{c|}{} & \multicolumn{5}{c|}{$\Delta P$} \\
\hline \multirow{4}{*}{ SOC } & $P_{\text {ref }}$ & BP & SP & Z & SN & BN \\
\cline { 2 - 7 } & B & CS & DG & DG & DG & DG \\
\cline { 2 - 7 } & M & CM & DM & DM & DG & DG \\
\cline { 2 - 7 } & S & CG & DS & DS & DG & DG \\
\hline
\end{tabular}

\subsubsection{Defuzzification}

The membership function of the output variable is shown in Fig. 9.

Fig. 10 shows the variation of $P_{\text {ref }}$ vs. the SOC and $\Delta P$. It shows the relationship between input and output variables obtained with fuzzy logic. 


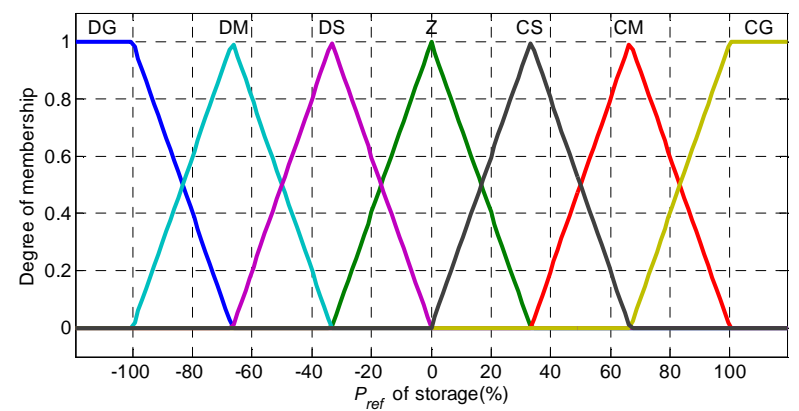

Fig. 9 Membership functions of output variable for the fuzzy energy management strategy

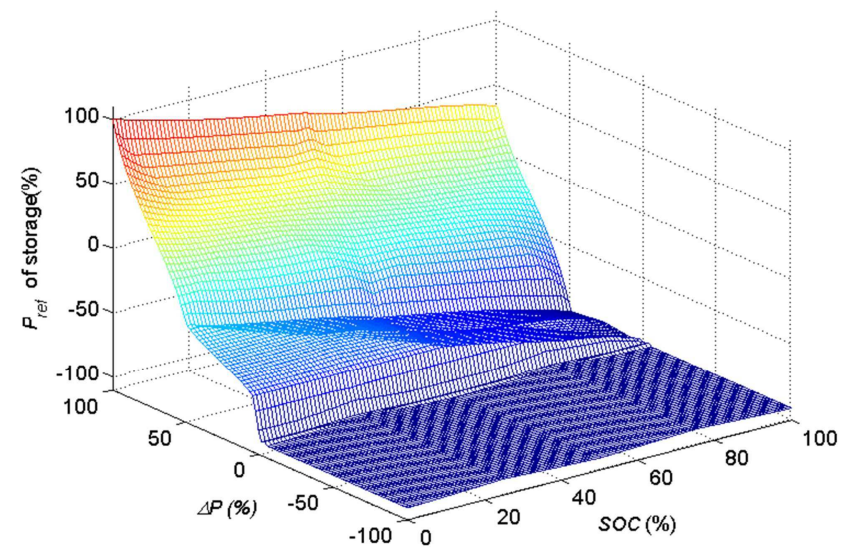

Fig. 10 Generated surface of PPW1 strategy

It can be noted, that in most cases, the storage system is discharged. When the $\Delta P$ is closed to 1 (power supplied is close to 0 ), the storage system will be charged to ensure the "consumer" characteristic of supermarket.

\section{Simulation results and comparison}

Fig. 11 shows the simulation results for a supermarket during one week with the help of Matlab Simulink. The Fuzzy logics explained above are implanted with the help of Fuzzy logic toolbox of Matlab. This paper just shows the results simulated for the January when the price period is the most complex, the other seasons are simulated as well with different PV production and consumption.

This simulation simulates a supermarket of $13058 \mathrm{~m}^{2}$, the peak power rating of the PV system is $1.16 \mathrm{MW}$. Capacity of the storage system is $1700 \mathrm{kWh}$.

It is noted that in Fig. 11, the supplied power doesn't pass over the subscribed power even when the load power of the supermarket passed it, because the storage system is used to adapt these thresholds. 


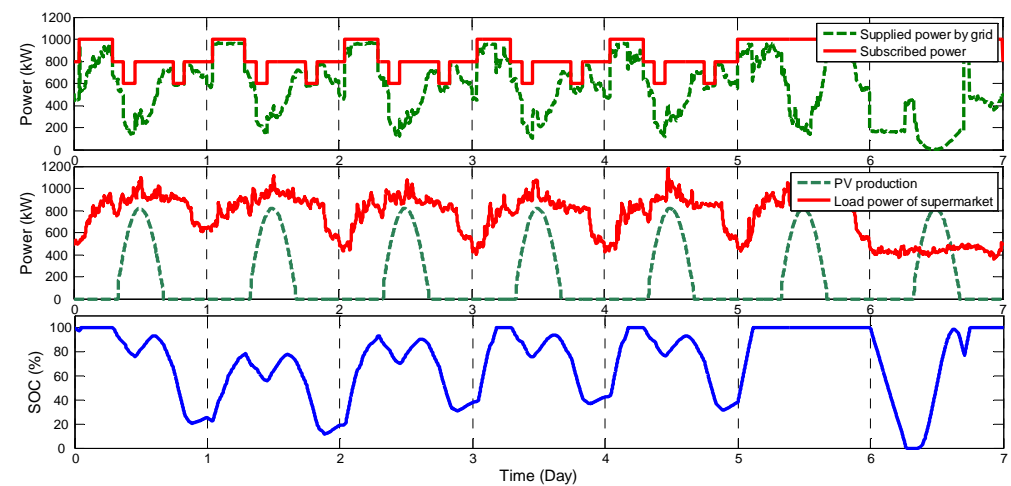

Fig. 11 Simulation results for one week

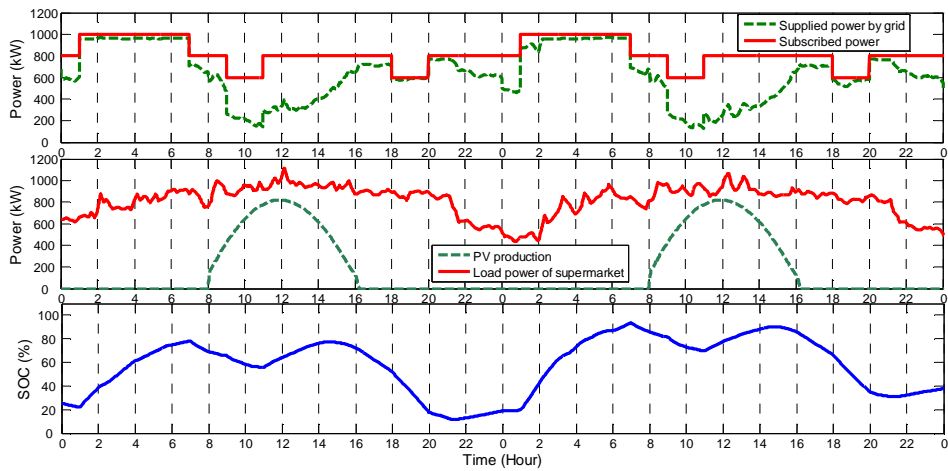

Fig. 12 Zoom of the simulation results for two open days (day 1 to day 3)

Fig. 12 shows a zoom of the simulation results for two open days. It can be noted that:

During $7 \mathrm{~h} \sim 9 \mathrm{~h}$ and $16 \mathrm{~h} \sim 18 \mathrm{~h}$, the storage system is discharged lightly to ensure that the consumption power don't pass through the subscribed power.

During $9 \mathrm{~h} \sim 11 \mathrm{~h}$, the peak period, thanks to the PV production in this period, the storage system is discharged lightly.

During $11 \mathrm{~h} \sim 13 \mathrm{~h}$, the shoulder period, because the situation admit (PV production and there's capacity to store), the storage is charged to ensure the consumption character and the energy availability.

During 18h 20h, there's no more PV production during the peak period, the storage system is discharged at maximum power (the slop of SOC is sharper) because the electricity price is the most expensive during this period.

During 20 21h, the storage is discharged lightly to ensure the consumption power do not pass through the subscribed power.

During $22 \mathrm{~h} \sim 1 \mathrm{~h}$, the storage is charged lightly because the situation admits it ( $\triangle P$ is big and SOC is small).

During $1 \mathrm{~h} \sim 6 \mathrm{~h}$, the storage system is charged at maximum power because the electricity price is the cheapest during this period. 


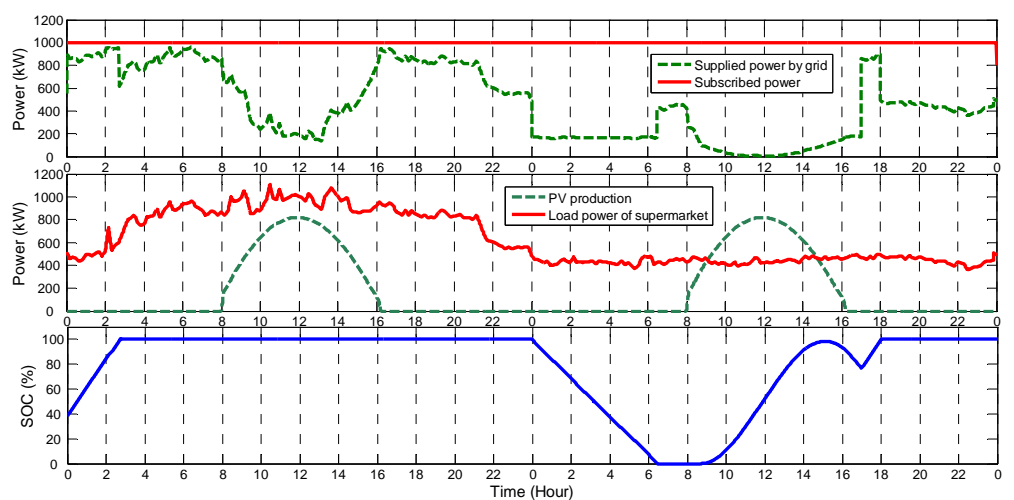

Fig. 13 Zoom of the simulation results for two off-peak days (day 5 to day 7)

Fig. 13 shows a zoom of the simulation results for two off-peak days including one closed day. It can be noted:

During $0 \mathrm{~h} \sim 3 \mathrm{~h}$ of Saturday, the storage is charged. Then during the daytime, the storage is not used.

During $0 \mathrm{~h} \sim \mathrm{h}$ of Sunday, the storage is discharged to empty by ensuring the "consumer" character (supplied power by grid is about $200 \mathrm{~kW}$ ).

During $9 \mathrm{~h} \sim 15 \mathrm{~h}$, when the PV production is greater than the consumption, the storage system begins to store the exceeding energy until the production is lower than consumption.

From $17 \mathrm{~h}$, after the sunset, the OPW1 strategy is applied. The storage begins to be charged until it is filled up.

Table 6 shows the different simulation results of different configurations.

Table 6 Comparison of the result with or without storage and PV systems associated with the supervision system

\begin{tabular}{|c|c|c|c|}
\hline & $\begin{array}{c}\text { Annual premium } \\
(€)\end{array}$ & $\begin{array}{c}\text { Consumption for } \\
\text { one week }(€)\end{array}$ & $\begin{array}{c}\mathrm{CO}_{2} \text { emissions for one } \\
\text { week }(\mathrm{T})\end{array}$ \\
\hline Case 1 & 79344 & 8782 & 11.604 \\
\hline Case 2 & 54747 & 6066 & 8.541 \\
\hline $\begin{array}{c}\text { The } \\
\text { difference }\end{array}$ & $-24597(-31.00 \%)$ & $-2716(-30.93 \%)$ & $-3.063(-26.40 \%)$ \\
\hline
\end{tabular}

Case 1 represents the configuration without storage and PV system, the subscribed power is chosen as $1200 \mathrm{~kW}$ for all the pricing period.

Case 2 represent the configuration with storage and PV system and the associated supervision system. The subscribed power is chosen as:

OPW:1000kW , SPW: 800kW, PPW: 600kW

The capacity of the storage system is chosen as $1700 \mathrm{kWh}$.

As shown in Table 6, thanks to the PV and the storage system, the electricity bill and the $\mathrm{CO}_{2}$ emissions can be significantly reduced. This estimation of the $\mathrm{CO}_{2}$ emissions is based on the realized production of the French Transmission System Operator (RTE France) [13] and the $\mathrm{CO}_{2}$ emissions estimation for every type of production [15]. Fig. 14 shows the comparison of $\mathrm{CO}_{2}$ emissions for a period of one week. 


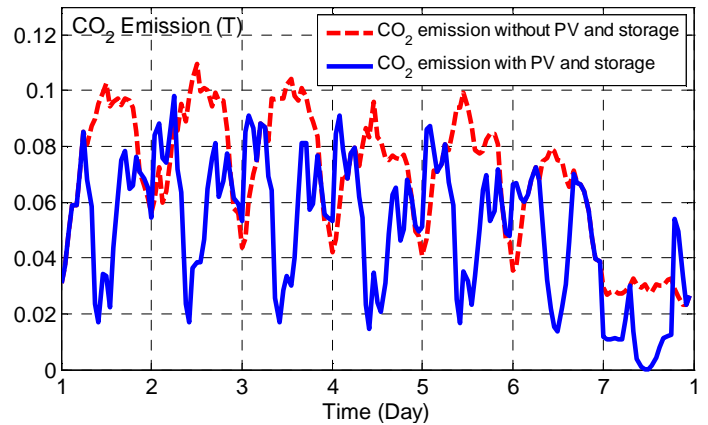

Fig. 14 Comparison of $\mathrm{CO}_{2}$ emissions

\section{Conclusion}

The energy management of a commercial building is a complex problem because of the PV production, the storage system, the variation of electricity price, the consumption and the purchase agreement etc. the energy management should consider these constraints and achieve several objectives at the same time. The general storage system can present different storage equipment such as battery, the cold room etc. The power reference issued from the supervision system can not only guide the storage system but also be a reference to guide the load shedding.

The fuzzy logic supervision strategy has been proven to be an adapted tool to solve this type of problem. This paper presents some fuzzy logic strategies to control the system in order to satisfy economic and ecological objectives.

Based on this work, the optimisation for long and medium term will be studied. As shown above, the output variable membership function can be always the same. The input variable could be standardized to a same membership function in a next step. The parameters of fuzzy logic will be optimised after this standardization.

\section{Acknowledgments:}

This work was supported by a financing from the French Environment and Energy Management Agency (ADEME) and the Regional Council Nord-Pas de Calais (France).

\section{References}

[1] V. Courtecuisse, M. EL Mokadem, B. Robyns, B. Francois, M. Petit and J. Deuse, "Association of wind turbine based dispersed generators and storage systems to participate in primary frequency control", 12th conference EPE 2007, September 2-5 2007, Aalborg, Denmark.

[2] L. Leclercq, B. Robyns and J. Grave, "Control based on fuzzy logic of a flywheel energy storage system associated with wind and diesel generators", Mathematics and Computers in Simulation, no. 63, pp. 271-280, June 2003.

[3] He ZHANG, Fabien MOLLET, Christophe SAUDEMONT and Benoit ROBYNS, "Experimental validation of Energy management strategies in a local DC Power Distribution System of More Electric Aircraft by using hybrid storage and dissipation 
systems", IEEE Transactions on Industrial Electronics VOL. 57, NO. 12, DECEMBER 2010, Pages:3905 3916.

[4] He ZHANG, Christophe SAUDEMONT, Benoît ROBYNS and Régis MEURET, "Comparison of different DC voltage supervision strategies in a local Power Distribution System of More Electric Aircraft", Elsevier Editorial System ${ }^{\text {TM }}$ for Mathematics and Computers in Simulation, Vol.81, Issue 2,Ocotbre 2010, Pages:263 276.

[5] Vincent Courtecuisse, Jonathan Sprooten, Benoît Robyns, Marc Petit, Bruno Francois and Jacques Deuse, "A methodology to design a fuzzy logic based supervision of Hybrid Renewable Energy Systems ", Elsevier Editorial System ${ }^{T M}$ for Mathematics and Computers in Simulation, Vol.81, Issue 2,Ocotbre 2010, Pages:208 224.

[6] Jonathan Sprooten, Vincent Courtecuisse, Benoît Robyns, Jacques Deuse, "Méthodologie de développement de superviseurs à logique floue de centrales multisources à base d'énergie renouvelable" European Journal of Electrical Engineering (EJEE) - 12/2009 pages : 553-583.

[7] P. Vas, "Artifical-Intelligence-Based Electrical Machine and Drive" Oxford, U.K.: Oxford Science, 1999.

[8] "Action Plan for Energy Efficiency (2007 - 2012)", 2011, http://europa.eu/legislation_summaries/energy/energy_efficiency/127064_en.htm

[9] "Green Paper. A European Strategy for Sustainable, Competitive and Secure Energy", Commission of the European communities, http://ec.europa.eu/energy/strategies/2006/2006_03_green_paper_energy_en.htm

[10] "directive 2006/32/ec of the european parliament and of the council of 5 april 2006 on energy end-use efficiency and energy services and repealing council directive 93/76/eec council directive 93/76/eec, 2006", http://eurlex.europa.eu/LexUriServ/LexUriServ.do?uri=OJ:L:2006:114:0064:0064:en:pdf

[11] "Action Plan for Energy Efficiency: Realising the Potential", Commission of the European Communities", 2006, http://ec.europa.eu/energy/action_plan_energy_efficiency/doc/com_2006_0545_en.pd $\underline{\mathrm{f}}$

[12] http://re.jrc.ec.europa.eu/pvgis/

[13] http://collectivites.edf.com/fichiers/fckeditor/Commun/Collectivites/pdf/Tarifs\% 20Verts\%2015_aout_2010.pdf

[14] http://clients.rte-france.com/lang/fr/visiteurs/vie/prod/realisation_production.jsp

[15] http://www.rte-france.com/fr/developpement-durable/maitriser-saconsommation-electrique/eco2mix-consommation-production-et-contenu-co2-de-1electricite-francaise\#emissionCO2 